\title{
Spinach aldolase interactions with rabbit, chicken, and fish muscle phosphofructokinase-1 ${ }^{*}$
}

\author{
Anita Williams, Ami Abbott, Jessica Chadwick, Alicia Thomas, Nathalia Cruz, \\ Alice Deng, Leah Ordinanza, John Tat, Percy Russell ${ }^{\#}$ \\ Department of Medical Education, School of Medicine, University of California, Division of Biology, San Diego, USA; \\ ${ }^{\#}$ Corresponding Author: prussell@ucsd.edu
}

Received 15 July 2013; revised 15 August 2013; accepted 19 August 2013

Copyright (C) 2013 Anita Williams et al. This is an open access article distributed under the Creative Commons Attribution License, which permits unrestricted use, distribution, and reproduction in any medium, provided the original work is properly cited.

\begin{abstract}
Previous studies showed that rabbit muscle phosphofructokinase-1 (PFK-1) activity losses due to dilution, due to inhibition by ascorbate, and due to some lithium salts were prevented by rabbit muscle aldolase. Chicken PFK-1 and fish PFK-1 interacted with ascorbate and were inhibited, consistent with a previously proposed function that ascorbate facilitates glycogen in resting muscle by inhibiting glycolysis. This report shows that a plant enzyme, spinach aldolase, has the same ability to prevent rabbit muscle PFK-1 activity loses as rabbit muscle aldolase and in some instances it was a better protector from activity losses than rabbit aldolase. Spinach aldolase also protected chicken and fish PFK-1s from inhibitions by ascorbate and from activity losses due to dilution. Prevention of losses PFK-1 activities from animal species by a plant protein, spinach aldolase, suggests an evolutionary conservative relationship between PFK-1s and aldolases.
\end{abstract}

Keywords: Phosphofructokinase-1; Spinach Aldolase Interactions; Carbonate Inhibitions; Rabbit Aldolase; Evolutionary Conservative Relationships; Ascorbate Inhibition

\section{INTRODUCTION}

Influenced by several metabolic intermediates, phosphofructokinase-1 (PFK-1) is the putative controlling enzyme of glycolysis. Compounds of potential therapeutic value were examined to determine their influence on PFK-1 activity. A report on the anti-metastatic effect of

"Declaration of interest statement: The authors report no declarations of interest. an ascorbic (AA) fatty acid derivative [1] suggested a study of other AA fatty acid derivatives. The effects of AA on muscle PFK-1 from three animal species, mammal, bird, and fish, were studied. A purpose of this study was to further demonstrate or not the role of $\mathrm{AA}$ as a facilitator of glycogen synthesis in resting muscle [2,3]. Because brain depends on glycolysis as an energy source and because lithium salts are used therapeutically in manic-depressive syndrome [4-9], another purpose was to study the ability of $\mathrm{Li}_{2} \mathrm{CO}_{3}$ to inhibit rabbit muscle (rm) PFK-1. Because spinach (sp) aldolase and rm aldolases share several characteristics, comparison of rm aldolases and $\mathrm{sp}$ aldolase interactions with mammalian PFK-1s was undertaken; the abilities of rm aldolase and sp aldolase were compared for their abilities to prevent inhibitions of rm PFK-1.

\section{MATERIALS}

\section{Biologicals and Chemicals}

Sigma-Aldrich Co was the commercial source of chemicals and enzymes in these experiments unless stated otherwise. Rabbit muscle (rm) aldolase (A 8811) was free of phosphofructokinase-1 (PFK-1), adenylate kinase (AK) and lactate dehydrogenase (LDH) under our conditions. Spinach (sp) aldolase preparation is described below.

\section{METHODS}

The PFK-1 buffers were $10 \mathrm{mM}$ Tris-phosphate, $\mathrm{pH}$ 8.0 (TP8) and all other solutions were $\mathrm{pH} 8.0$ unless stated otherwise. Temperatures were $25^{\circ} \mathrm{C}$.

\subsection{Statistics}

Each experiment (n) was done in duplicate by other hands; the minimum number of experiments was $n=6$. 
Data were acceptable when the standard error of the mean (SEM) was less than $\pm 10 \%$. Error bars represent $\pm 10 \%$ of the average SEM.

\subsection{PFK-1 Preparations}

Rabbit muscle (Oryctolagus cuniculus), chicken muscle (cm, Gallus gallus) and red snapper muscle (fm, Lutjanus peru) phosphofructokinase-1s (PFK-1, EC 2.7.1.56) were prepared by our laboratory from frozen tissue after a method by Kemp [10]. After determining that a PFK-1 preparation was void of aldolase activity, PFK-1 preparations were stored at $4{ }^{\circ} \mathrm{C}$ as $60 \%$ saturated ammonium sulfate precipitates. Precipitates of rm PFK-1 were useful in experiments for several weeks; cm PFK-1 and the fm PFK-1 ammonium sulfate precipitates were not so stable - cm PFK-1 was used up to 2 weeks after preparation and fm PFK-1 was used up to a few days after preparation. A criterion for experimental use was an activity of $50 \%$ or greater than the original preparation. It was determined that under these conditions there was no difference from a fresh preparation.

At $3.1 \pm 0.1 \mathrm{eu} / \mathrm{mL}$, stock PFK-1 solutions were considered $3 \mu \mathrm{M}$ PFK-1 in $10 \mathrm{mM}$ TP8. Dilutions were made from $3 \mu \mathrm{M}$ PFK-1 stock solutions to final concentrations given in individual experiments.

\subsection{Criteria for PFK-1 Purity}

Primary criteria for PFK-1 preparations were the absence of aldolase, $\mathrm{LDH}$, and AK activities. The purity of PFK-1 was also determined using enzyme activities and SDS polyacrylamide gel electrophoresis (Figure 1) of rm
PFK-1 preparations. SDS PAGE used 12 percent crosslinked gels and the Mini-Protean II Cell assembly as given previously [11]. Bio-Rad gels were silver stained for proteins using the procedure of Morrissey [12].

\subsection{Standard PFK-1 Assay}

PFK-1 activities, F 6-P (fructose 6-phosphate) + ATP = F 1,6-BP (fructose 1,6 -bisphosphate), were measured with a modification of the method by Anderson et al. [13]. A 1.0 assay mixture contained $2 \mathrm{mM} \mathrm{F} 6-\mathrm{P} ; 1 \mathrm{mM}$ ATP (A 7699); 3 mM MgCl $2 ; 0.13$ mM NADH (N 1161); $1.7 \mathrm{eu} / \mathrm{mL}$ glyceraldehyde 3-phosphate dehydrogenase (G 0763); $18 \mathrm{eu} / \mathrm{mL}$ triose phosphate isomerase (G1881); $1.3 \mathrm{eu} / \mathrm{mL}$ aldolase (A 8811); and $10 \mathrm{mM}$ TP8 buffer as final concentrations. A molar absorptivity value of 6220 converted NADH absorbance changes to $\mu$ moles of product formed. One PFK-1 enzyme unit (eu) of activity is defined as formation of $1 \mu$ mole of $\mathrm{NAD}^{+} / \mathrm{min}$.

\subsection{Dilute PFK-1 Assays}

When PFK-1 activity rates were below $0.05 \mathrm{eu} / \mathrm{min}$ in a $100 \mu \mathrm{L}$ sample, assay system components in the Standard PFK-1 assay above were concentrated to 10 times final assay concentrations into $0.1 \mathrm{~mL}$. This allowed PFK-1 test samples up to $0.9 \mathrm{~mL}$ in the assay for more accurate rate activity measurements.

\subsection{Aldolase Assay}

Reagents for measurement of aldolase activity were the same as the Standard PFK-1 assay above, except that

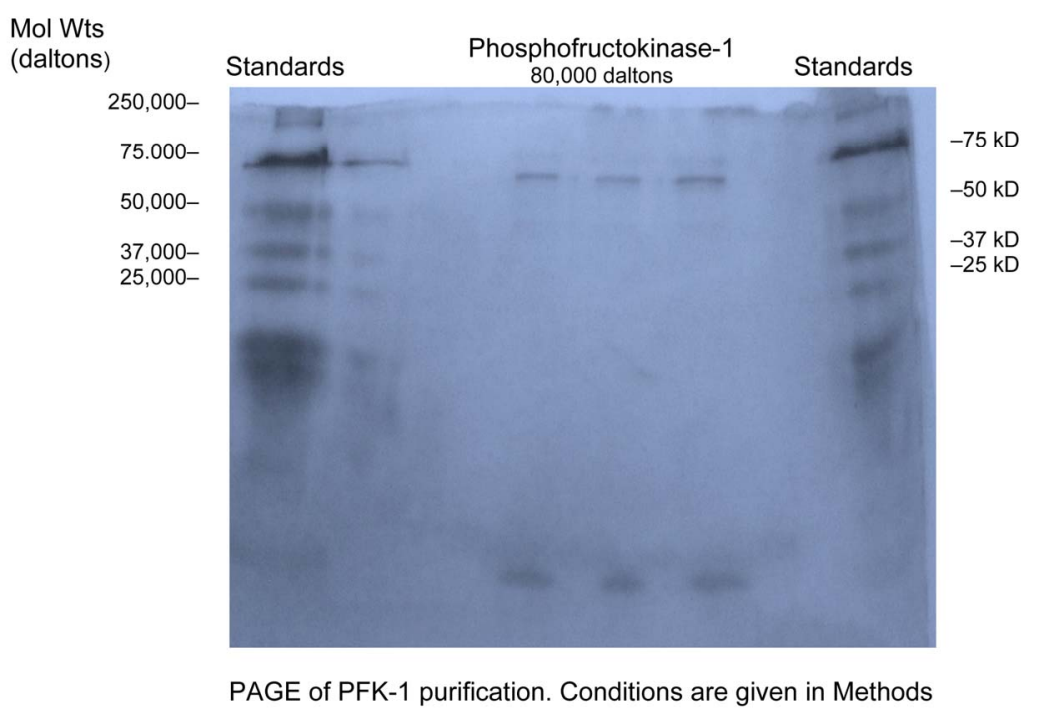

Figure 1. Polyacrylamide gel electrophoresis of a typical PFK-1 preparation. On the right and left is a polyacrylamide gel electrophoresis with protein standards and their molecular weights. In the center is a sample of a typical PFK-1 preparation. 
$2 \mathrm{mM}$ F 6-P and $1 \mathrm{mM}$ ATP were omitted and replaced by $2 \mathrm{mM} F$ 1,6-BP. One eu of aldolase activity was defined as formation of $1 \mu \mathrm{M} \mathrm{NAD}^{+} / \mathrm{min}$.

\subsection{LDH Assay}

Measurement of LDH activity was according to Vassault [14]. One eu of LDH activity was defined as formation of $1 \mu$ mole of $\mathrm{NAD}^{+} / \mathrm{min}$.

\subsection{Rabbit Muscle Aldolase}

Rabbit muscle aldolase was obtained from Sigma-Aldrich Co and was void of any PFK-1 activity. The percent contamination of other enzymes, based on eu/mL were as follows: $\mathrm{LDH}, 0.03 \mathrm{eu} / \mathrm{mL}$; enolase, $0.1 \mathrm{eu} / \mathrm{mL}$; and adenylate kinase, $0.2 \mathrm{eu} / \mathrm{mL}$, none of which interfered with losses or preventions of losses of PFK-1 activities.

\subsection{Spinach Aldolase Preparation}

The preparation of sp aldolase used was reported previously [15]. Figure 2 shows a polyacrylamide gel electrophoresis (PAGE) of a typical sp aldolase preparation. Purities of sp aldolase was determined by enzymatic determinations of other enzyme contaminants and by SDS polyacrylamide gel PAGE were run with 12 percent cross-linked gels and silver stained for proteins according to Morrissey [12]. The PAGE shows a contamination of AK at $20-25 \mathrm{kD}$ that was difficult to remove without significant losses of $\mathrm{sp}$ aldolase. It was determined that
AK had no effect on either inhibitions of PFK-1 or loss of activity due to dilution. When there was an occasional, small contamination of sp PFK-1 activity in sp aldolase, the appropriate PFK-1 activity was subtracted from samples containing sp aldolase.

\subsection{Addition to Samples}

The enzyme to be tested was added last from a $3 \mu \mathrm{M}$ stock solution. The order of reagent additions to final samples concentrations were as follows: buffer, $10 \mathrm{mM}$ TP8; PFK-1; aldolase; inhibitors; and test-enzyme. A 45 min incubation allowed activities losses due to dilution to stabilize, followed by an $1 \mathrm{hr}$ incubation after inhibitor additions, when activities were determined.

\subsection{Ascorbate-Fatty Acid Derivatives}

The L-ascorbate (AA) fatty acid derivatives were obtained from TCI and Alfa Aesar.

Structures of the AA-fatty acid derivatives are shown in Figure 3.

\subsection{Measurements of Protein Concentrations}

PFK-1 protein concentrations during purification procedures were determined using the following formula: $\mathrm{mg}$ protein $/ \mathrm{mL}=1.55 \mathrm{~A}_{280}-0.76 \mathrm{~A}_{260}$, where $\mathrm{A}_{280}$ and $\mathrm{A}_{260}$ are absorbencies at $280 \mathrm{~nm}$ and $260 \mathrm{~nm}$, respectively [16].

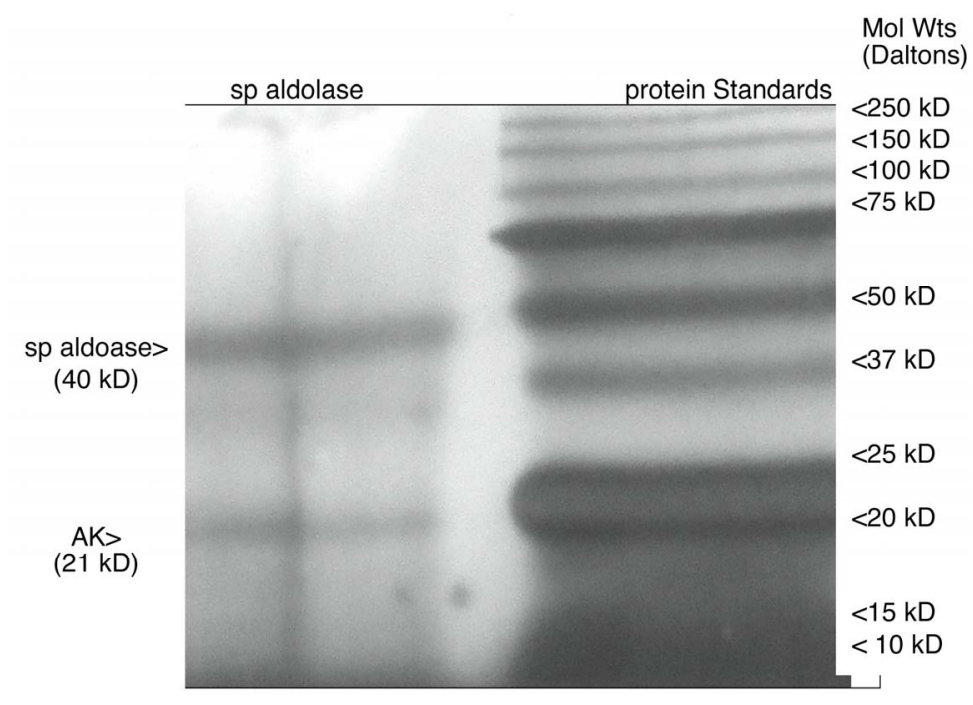

Figure 2. Polyacrylamide gel electrophoresis of a typical sp aldolase preparation; On the right is a polyacrylamide gel electrophoresis with protein standards and their molecular weights. On the left is a sample of a sp aldolase preparation. The major band on the left is associated with sp aldolase and the minor band is associated adenylate kinase (AK, $21 \mathrm{kD})$, which had no effect on activity losses due to dilution, activity losses due to AA inhibition, or prevention of activity losses due to the presence rm aldolase. 
Structure of ascorbate fatty acid derivatives

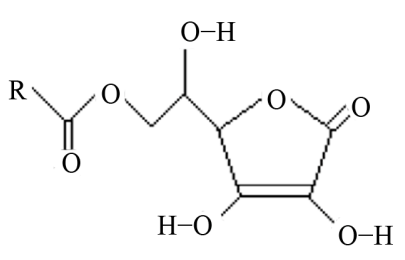

6 palmityl ascorbate (AAP) $\mathrm{R}=\mathrm{CH}_{3}\left(\mathrm{CH}_{2}\right)_{14}^{-}$

6 stearyl ascorbate (AAS)

$\mathrm{R}=\mathrm{CH}_{3}(\mathrm{CH} 2)_{16}-$

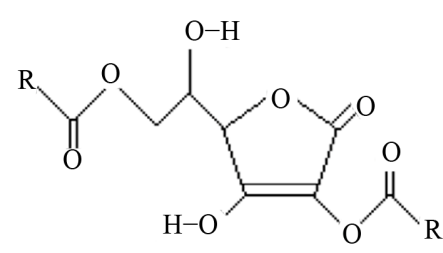

2,6 dibutyryl ascorbate (AADB) $\mathrm{R}=\mathrm{CH}_{3}(\mathrm{CH} 2)_{2}^{-}$

2,6 dibutyryl ascorbate (AADP) $\mathrm{R}=\mathrm{CH}_{3}(\mathrm{CH} 2)_{14}^{-}$

Figure 3. Structure of ascorbate fatty acid derivatives.

\section{RESULTS}

Activities relative to 0-time controls are shown in Figures 4 and 5 for $\mathrm{cm}$ PFK-1 and fm PFK-1 because of the large differences in activities at various enzyme concentrations: $30 \mathrm{nM}$ PFK-1, $100 \mathrm{nM}$ PFK-1, and $300 \mathrm{nM}$ PFK-1. Figures 4(a) and (b) show characteristic differences between cm PFK-1 and fm PFK-1 dilutions with time.

Figure 4(a) shows that losses of activity were $\mathrm{cm}$ PFK-1 concentration dependant. Loss of activities due to dilutions to $30 \mathrm{nM} \mathrm{cm} \mathrm{PFK-1} \mathrm{( \square )} \mathrm{or} \mathrm{to} 100 \mathrm{nM} \mathrm{cm}$ PFK-1 $(\Delta)$ showed an 80 percent activity loss, while activity lose due to dilutions to $300 \mathrm{nM} \mathrm{cm} \mathrm{PFK-1} \mathrm{(O)}$ showed a 30 percent activity loss. Activities can be shown to remain stable for more than $2 \mathrm{~h}$. Prevention against some of these activity losses due to dilution was provided by the presence of $5 \mu \mathrm{M} \mathrm{rm}$ aldolase $(\boldsymbol{\bullet}, \boldsymbol{\Delta}, \bullet)$.

In Figure 4(b), fm PFK-1 shows a different pattern from cm PFK-1. All dilutions $(\square, \Delta, \mathrm{O})$ show about 70 percent activity losses. The presence of $5 \mu \mathrm{M}$ rm aldolase $(\boldsymbol{\square}, \boldsymbol{\Delta}, \bullet)$ also affected fm PFK-1 differently from cm PFK-1. Initially, $300 \mathrm{nM}$ fm PFK-1 (•) always showed stimulations of activity immediately after dilution in the presence of rm aldolase. Activity losses due to dilution to $100 \mathrm{nM} \mathrm{cm} \mathrm{( \Delta )} \mathrm{and} 300 \mathrm{nM} \mathrm{cm} \mathrm{PFK-1} \mathrm{(O)}$ were completely prevented by rm aldolase. Prevention of $30 \mathrm{nM}$ fm PFK-1 ( $\square$ ) activity losses due to dilution were small by comparisons with $100 \mathrm{nM}$ PFK-1 and $300 \mathrm{nM}$ fm PFK-1. Neither cm PFK-1 nor fm PFK-1 were so well protected from activity losses due to dilution by $\mathrm{rm}$ aldolase as was rm PFK-1 [2] where it was shown that dilutions below $200 \mathrm{nM}$ rm PFK-1 resulted in tetramer dissociations to less active dimers or monomers.

Inhibitions of cm PFK-1 and fm PFK-1 by AA were examined. Figures 5(a) and (b) show the activity losses of cm PFK-1 and fm PFK-1 due to dilutions and due to inhibition by AA and effects of rm aldolase against these losses. The relative activities in Figure 4 differ from the relative activities in Figure 5. All activities of PFK-1 concentrations in Figure $\mathbf{4}$ are relative to 0 -times activeties in the absence of AA and the absence (open symbols) or presence of aldolase (closed symbols); each set has a 0 -time value. Both cm PFK-1 and fm PFK-1 were more sensitive to AA inhibition than rm PFK-1, which was not inhibited by AA above $200 \mathrm{nM}$ rm PFK-1 [2]. The relative activities in Figures 5(a) and (b) shows the prevention of activity losses due to dilution and due to AA inhibition of cm PFK-1 and fm PFK-1 by rm aldolase were similar; the 0-time values are based upon the on the 0 -time values in the absence aldolase only for each set.

It was previously shown that 0.1 molar monovalent carbonates salts or sulfates inhibited rm PFK-1 [2,18]. Tables 1(a) and (b) show percent inhibitions of $30 \mathrm{nM}$ cm PFK-1 and 30 nM fm PFK-1 by monovalent salts; the negative values show the percent stimulation. The conspicuous differences between cm PFK-1 and fm PFK-1 inhibitions were with $\mathrm{Li}_{2} \mathrm{CO}_{3}$ that almost completely inhibited cm PFK-1, while fm PFK-1 was less than 50 percent inhibited. Lithium salts were particular of interest because of their use in manic-depressive disorder therapy and the many speculations for their therapeutic value [4-9]. The $\mathrm{Li}_{2} \mathrm{CO}_{3}$ inhibition of PFK-1 and the dependency of brain on glycolysis as an energy source add the of inhibition glycolysis [5] as a possible mechanism of its action. Glycolysis is also considered the major energy source in cancer cells $[19,20]$ and the report [1] that an AA fatty acid derivative prevented metastasis in mice and cancer growth in cell culture prompted testing other AA fatty acid derivatives on their abilities to inhibit 30 nM rm PFK-1.

Figures 6(a)-(d) compare the ability of rm aldolase and sp aldolase to prevent activity loses of rm PFK-1 due to dilution, due to inhibitions by AA or AA fatty acid derivatives. Figures 6(a)-(d), show both rm aldolase and sp aldolase prevented losses of activities due to dilution in all instances. About half to two-thirds of the predicted activity of $3 \mu \mathrm{M}$ rm PFK-1 stock solutions diluted to 30 

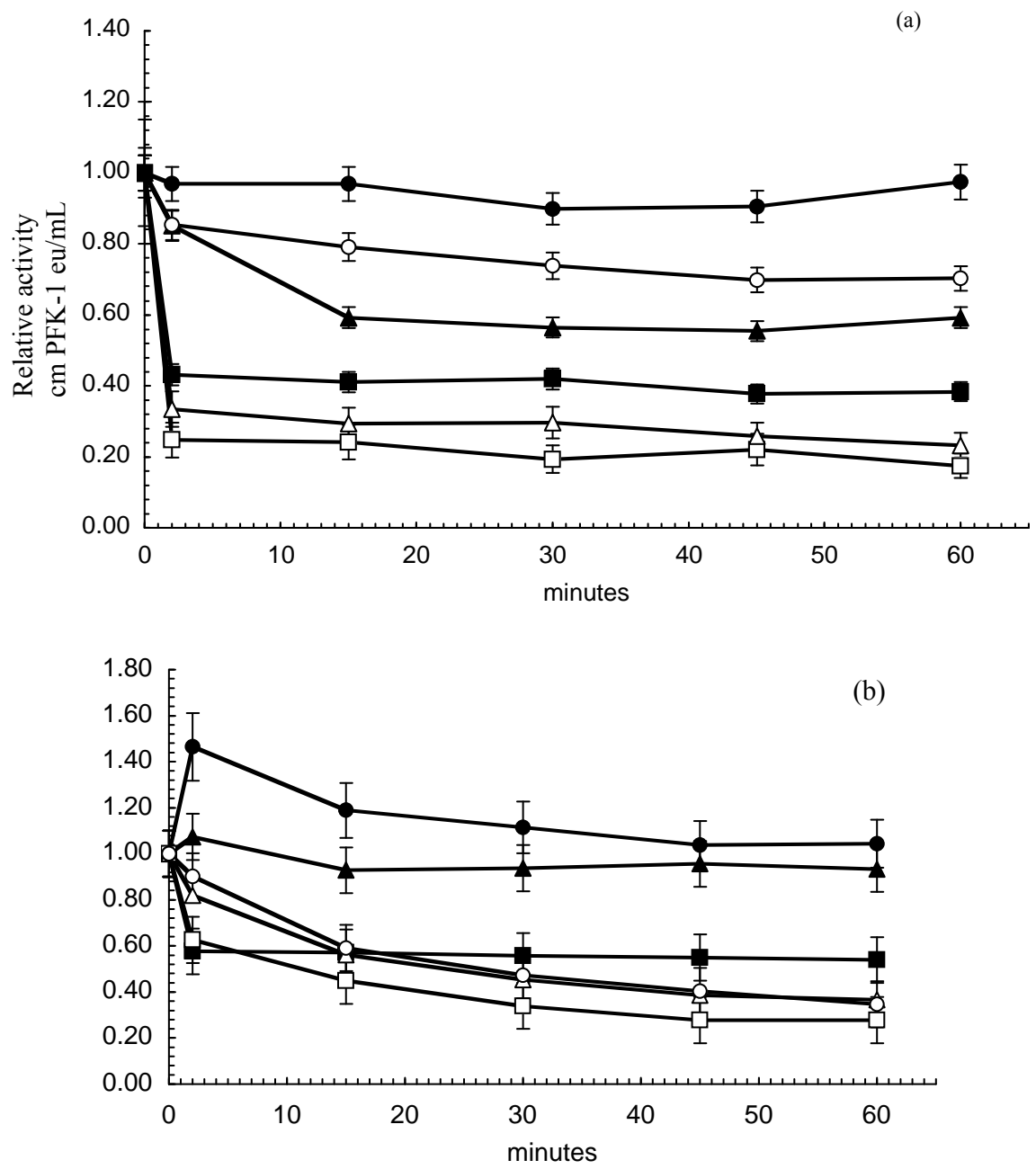

Figure 4. Loss of PK-1 activities due to dilution and the effect of aldolase. Figure 4 and Figure 4(b) show activity loses with time of cm PFK-1 (a) and fm PFK-1 (b) at various PFK-1 concentrations and the effects of $5 \mu \mathrm{M}$ rm aldolase. Symbols for PFK-1 concentrations are 30 nmolar $(\square, \mathbf{\bullet}), 100$ nmolar $(\Delta, \boldsymbol{\Delta})$ and 300 nmolar $(\mathrm{O}, \bullet)$ for the absence of 5 $\mu \mathrm{M} \mathrm{rm}$ aldolase (open symbols) and presence of $5 \mu \mathrm{M}$ rm aldolase (closed symbols). Each 0 -time value for a PFK-1 concentration set was estimated activities from their $3 \mu \mathrm{M}$ PFK-1 stock solutions independently from the others; In Figure 4(a), The 0-time estimates of the cm PFK-1 dilutions were as follows: $30 \mathrm{nM}$ cm PFK-1 $=0.0091 \mathrm{eu} / \mathrm{mL} ; 100 \mathrm{nM} \mathrm{cm}$ PFK-1 $=0.062 \mathrm{eu} / \mathrm{mL}$; and $300 \mathrm{nM} \mathrm{cm}$ PFK-1 $=0.265 \mathrm{eu} / \mathrm{mL}$. In Figure 4(b) the estimate of the fm PFK-1 dilutions were $30 \mathrm{nM}$ fm PFK-1 = 0.0192; eu/mL; $100 \mathrm{nM}$ fm PFK-1 = $0.0755 \mathrm{eu} / \mathrm{mL}$; and $300 \mathrm{nM}$ fm PFK-1 $=0.168 \mathrm{eu} / \mathrm{mL}$. The relative activities shown are independently based on 0 -time values of each set of dilutions. Other conditions are given in Methods.

nM PFK-1 is lost [2] in the absence of aldolase. In Figure 6(a), differences between the two aldolases were in their abilities to prevent inhibitions of $30 \mathrm{nM}$ rm PFK-1 by AA. Rm aldolase partially prevented inhibition by AA; sp aldolase not only prevented inhibition by AA but also prevented activity loss due to dilution in the presence of AA. In Figure 6(b), rm aldolase prevented inhibition by AAP while sp aldolase not only prevented inhibition by AAP but also prevented activity lost due to dilution. In Figure 6(c), neither rm aldolase nor sp aldolase pre- vented losses due to AAS. In Figure 6(d), rm aldolase prevented inhibition by AADP but had no effect on preventing losses due to dilution in the presence of AADP; sp aldolase, on the other hand, prevented losses of activiity due to dilution and prevented inhibition by AADP simultaneously.

In summary, while both rm aldolase and sp aldolase protect $30 \mathrm{nM}$ rm PFK-1 from activity losses due to dilution, sp aldolase was superior in protecting against inhibitions by AA, AAP and AADP (Figures 6(a), (b) and 

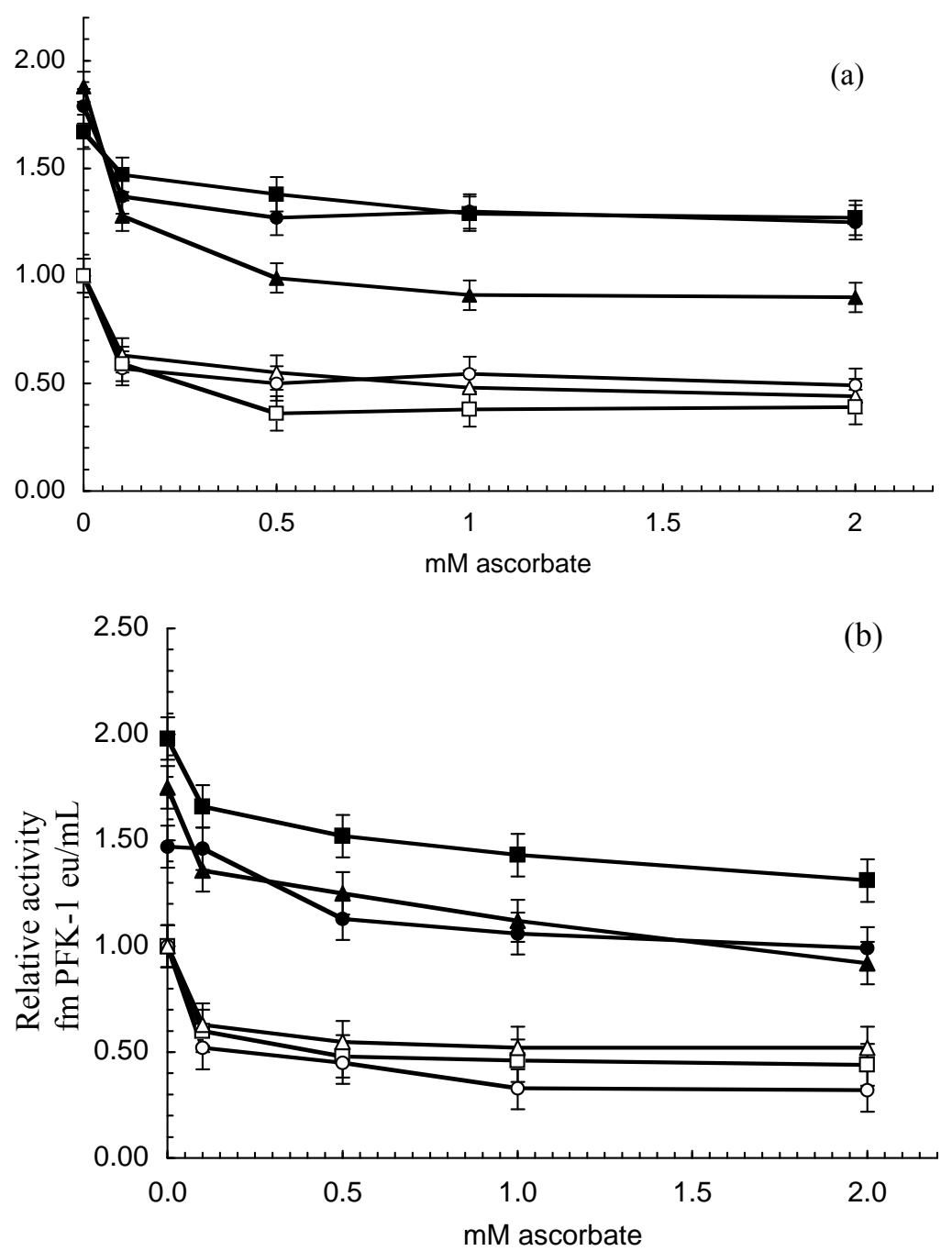

Figure 5. The effect of $\mathrm{rm} 5 \mu \mathrm{M}$ aldolase on AA inhibitions. Symbols are the same as in Figures 4. In Figures 5 the 0-time values of each PFK-1 concentration set is based on the 0 -time value with no aldolase (open symbols) and no AA. The 0-time values were as follows: in Figure 5(a) $30 \mathrm{nM} \mathrm{cm} \mathrm{PFK-1}=0.0086$ $\mathrm{eu} / \mathrm{mL} ; 100 \mathrm{nM} \mathrm{cm}$ PFK-1 $=0.056 \mathrm{eu} / \mathrm{mL}$; and $300 \mathrm{nM} \mathrm{cm} \mathrm{PFK-1}=0.258$ $\mathrm{eu} / \mathrm{mL}$. In Figure 5(b), $30 \mathrm{nM}$ fm PFK-1 = 0.0188; eu/mL; $100 \mathrm{nM}$ fm PFK-1 = $0.0743 \mathrm{eu} / \mathrm{mL} ; 300 \mathrm{nM}$ fm PFK-1 $=0.165 \mathrm{eu} / \mathrm{mL}$. Other conditions are given in Figure 4 and in Methods.

(d)). Both rm aldolase and sp aldolase were ineffective against inhibition by AAS (Figure 6(c)).

Figures 7(a)-(c) compare the abilities rm aldolase and sp aldolase to prevent $30 \mathrm{nM}$ rm PFK-1 inhibitions by carbonate salts. Figure 7(a) shows that inhibitions by $\mathrm{K}_{2} \mathrm{CO}_{3}$ were prevented by both rm aldolase and sp aldolase and also prevented activity losses due to dilution in the presence of $\mathrm{K}_{2} \mathrm{CO}_{3}$; In Figure 7(b), neither rm aldolase nor sp aldolase prevented inhibition by $\mathrm{Li}_{2} \mathrm{CO}_{3}$. In Figure 7(c), inhibition by $\mathrm{Na}_{2} \mathrm{CO}_{3}$ was prevented by $\mathrm{rm}$ aldolase and sp aldolase but sp aldolase also prevented losses of activity due to dilution in the presence of $\mathrm{Na}_{2} \mathrm{CO}_{3}$.

\section{DISCUSSION}

The results demonstrated characteristics common among PFK-1s purified from three species-mammals, fish, and bird, supporting the role of AA as a facilitator of glycogen synthesis $[2,3]$ in animals. Both cm PFK-1 and fm PFK-1 inhibitions were similar to rm PFK-1 activity with respect to losses due to dilution (Figure 4), AA (Figure 5), AA fatty acid derivatives (Figure 6), carbonate salts, and sulfate salts (Table 1, Figure 7). The same figures also showed sp aldolase was similar to rm aldolase in preventing these rm PFK-1 activity losses with at least the same effectiveness. These outcomes appear to 
(a)

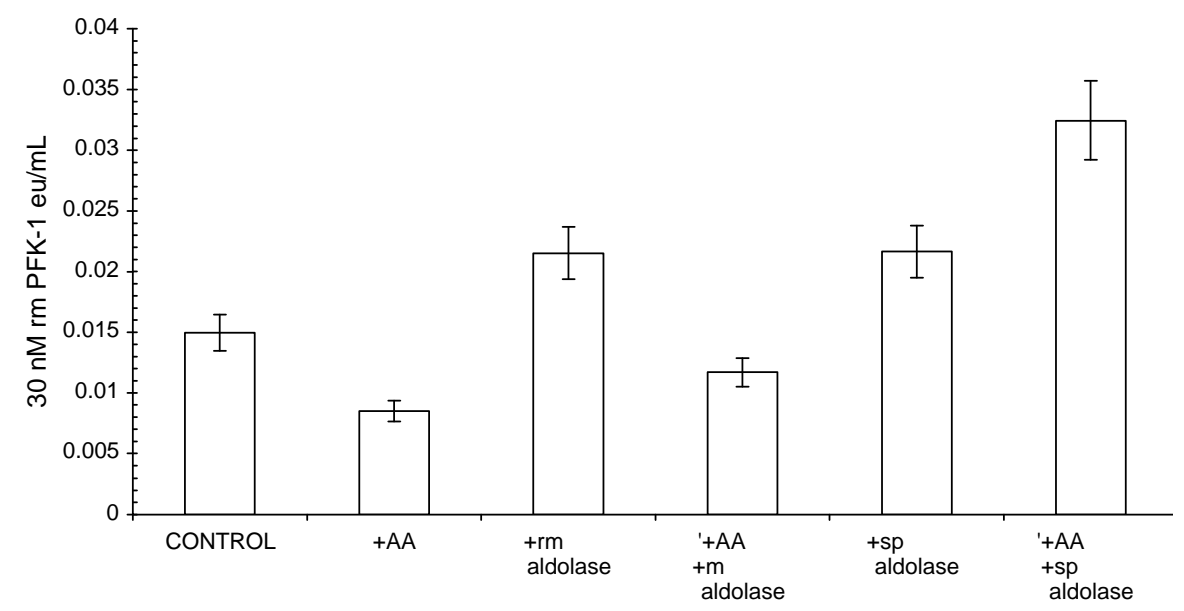

(b)

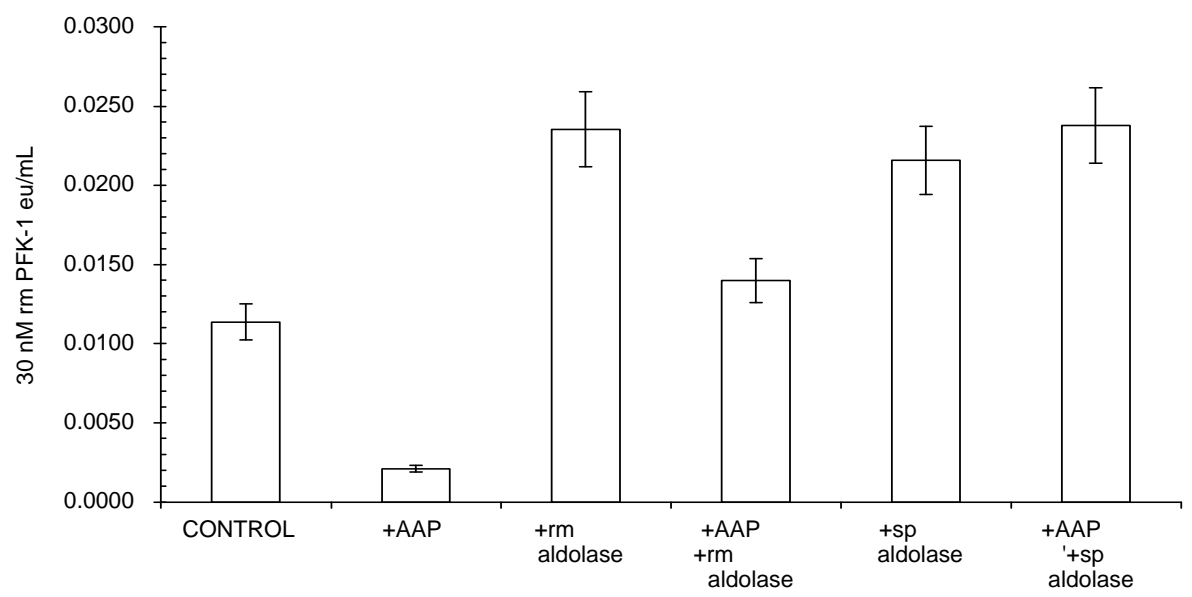

(c)
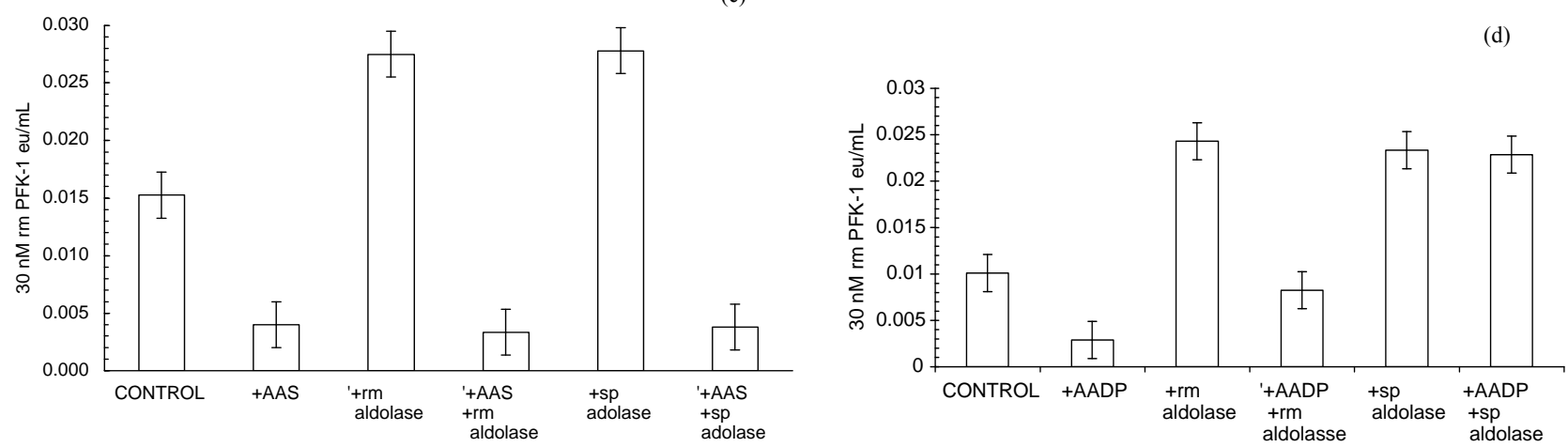

Figures 6. Comparisons of rm aldolase and sp aldolase effects on inhibitions of $30 \mathrm{nM}$ rm PFK-1 by AA, AAP, AAS, and AADP. Final concentrations of inhibitors were as follows: $2 \mathrm{mM} \mathrm{AA} ; 20 \mu \mathrm{M}$ AAP; $20 \mu \mathrm{M}$ AAS; and $10 \mu \mathrm{M}$ AADP. The activities of initial stock solutions for dilutions to $30 \mathrm{nM}$ PFK-1 were as follows: (a) $2.81 \mathrm{eu} / \mathrm{mL}$; (b) $2.68 \mathrm{eu} / \mathrm{mL}$; (c) $2.78 \mathrm{eu} / \mathrm{mL}$; and (d) $2.64 \mathrm{eu} / \mathrm{mL}$. Other conditions are given in Methods.

reflect a conservation of PFK-1 characteristics among other species and a conservation of a relationship between PFK-1s and aldolases.

Activity losses due to dilutions of cm PFK-1 were more similar to rm PFK-1 than were dilutions of fm
PFK-1. At dilutions to about $300 \mathrm{nM} \mathrm{cm}$ PFK-1, activity losses due to dilution (Figure 4) started to occur, whereas activity losses due to dilution occurred below $200 \mathrm{nM}$ rm PFK-1 [2], suggesting that rm PFK-1 tetramer is less likely to dissociate than cm PFK-1. Fm 

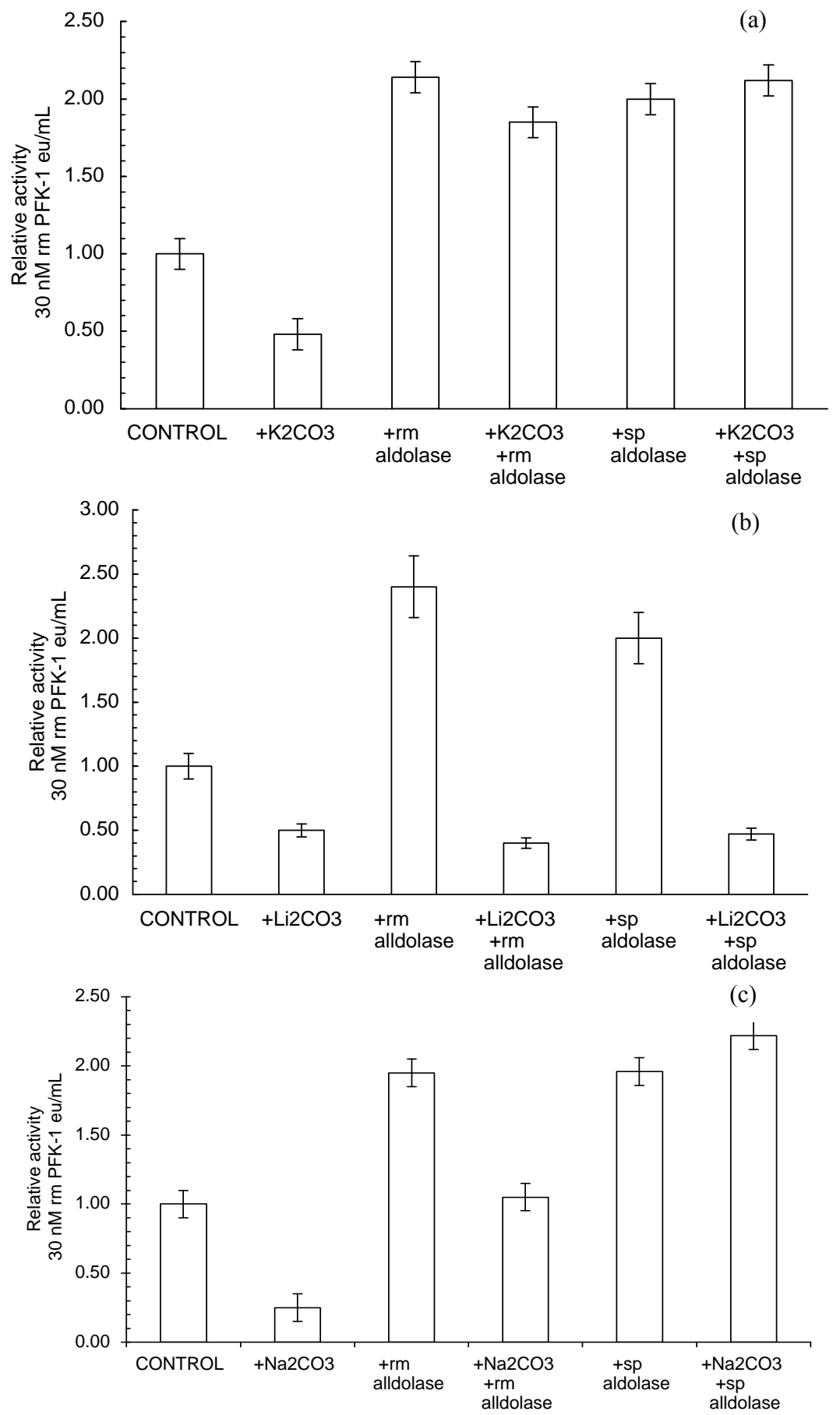

Figures 7. (a)-(c) Comparisons of rm aldolase and sp aldolase effects on inhibittions of $30 \mathrm{nM}$ rm PFK-1 by $0.1 \mathrm{M}$ monovalent salts. Activities of initial stock solutions for dilutions to $30 \mathrm{nM}$ rm PFK-1 were as follows: (a) $2.91 \mathrm{eu} / \mathrm{mL}$; (b) $2.77 \mathrm{eu} / \mathrm{mL}$; and (c) $2.93 \mathrm{eu} / \mathrm{mL}$. Other conditions were the same as in Figure 6.

PFK-1 appeared to lose about the same activity at all dilutions tested, suggesting that it is most likely to dissociate with dilution. It was previously determined that $\mathrm{rm}$ PFK-1 activity loses were due to dissociations from tetramers to less active dimers or monomers [2].
Figures 5(a) and (b) show that preventions of AA inhibitions by $\mathrm{rm}$ aldolase were similar for $\mathrm{cm}$, fm PFK-1 and rm PFK-1 [2,3]. Figure 5(b) shows that aldolase (closed symbols) protects against activity losses due to dilution and activity losses due to AA inhibition. 
Table 1. Inhibition of $30 \mathrm{nM} \mathrm{cm}$ PFK-1 and $30 \mathrm{nM}$ fm PFK-1 by monovalent salts. A minus sign $(-)$ indicates the percentage of stimulation. (a) Percent inhibition of $30 \mathrm{nM} \mathrm{cm}$ PFK-1 by $0.1 \mathrm{M}$ monovalent salt; (b) Percent inhibition of $30 \mathrm{nM} \mathrm{fm}$ PFK-1 by $0.1 \mathrm{M}$ monovalent salts.

(a)

\begin{tabular}{ccccc}
\hline CATIONS & \multicolumn{4}{c}{ ANIONS } \\
\hline & Acetate & Carbonate & Chloride & Sulfate \\
\hline Lithium & 5 & 95 & 4 & 72 \\
Potassium & -5 & 60 & -13 & 48 \\
Sodium & 9 & 22 & 12 & 31 \\
\hline
\end{tabular}

(b)

\begin{tabular}{ccccc}
\hline Cations & \multicolumn{4}{c}{ Anions } \\
\hline & Acetate & Carbonate & Chloride & Sulfate \\
\hline Lithium & 4 & 43 & 6 & 63 \\
Potassium & 4 & 39 & 9 & 53 \\
Sodium & 18 & 46 & 4 & 58 \\
\hline
\end{tabular}

Tables 1(a) and (b) show that $\mathrm{cm}$ PFK-1 and fm PFK-1 carbonate and sulfate salt inhibitions follow inhibition patterns similar to rm PFK-1 [2,18]. Generally, acetates and chlorides were poor or not inhibitors and carbonates and sulfates were good inhibitors of rm PFK-1. Lithium salts inhibitions were of interest particular because of their therapeutic use in manic-depressive syndrome [4-9] and because of brain dependence on glycolysis.

Figures 4(a)-(d) show inhibitions of rm PFK-1 by AA fatty acid derivatives and $\mathrm{AA}$ and compares the abilities of $\mathrm{rm}$ aldolase and sp aldolase to prevent these inhibitions. The AA fatty acid derivatives and AA showed different inhibition patterns. Sp aldolase appeared to be superior to rm aldolase in preventing AA inhibitions. The AA fatty acid derivatives were several-fold more inhibitory to rm PFK-1 than AA. It was proposed by the authors [1] that the therapeutic value of AA2P6L in mouse cancer was due to its antioxidant properties. Since cancer cells are so dependent upon glycolysis as an energy source $[19,20]$ and in view of the inhibitory character of AA fatty acid derivatives here, an alternate view is that the therapeutic value of AA2P6L [1] was due to its ability inhibit PFK-1 and glycolysis. In this regard, it may be significant that $\mathrm{rm}$ aldolase does not prevent $\mathrm{Li}_{2} \mathrm{CO}_{3}$ inhibition of rm PFK-1.

Figures 5(a)-(c) show similarities between the ability of $\mathrm{rm}$ aldolase and sp aldolase to prevent inhibitions of rm PFK-1 by carbonate salts; as in previous Figures, both aldolases prevented activity loses due to dilution. In
Figure 7(a), $\mathrm{K}_{2} \mathrm{CO}_{3}$ inhibitions were prevented by both $\mathrm{rm}$ and sp aldolases and prevented losses due to dilutions even in the presence of $\mathrm{K}_{2} \mathrm{CO}_{3}$. In Figure 7(b), neither $\mathrm{rm}$ aldolase nor sp aldolase prevented inhibitions of $\mathrm{rm}$ PFK-1 by $\mathrm{Li}_{2} \mathrm{CO}_{3}$. In Figure 7(c), sp aldolase was both effective in preventing inhibitions by $\mathrm{Na}_{2} \mathrm{CO}_{3}$ but sp aldolase also prevented activity losses due to dilution even in the presence of the $\mathrm{Na}_{2} \mathrm{CO}_{3}$, as with $\mathrm{K}_{2} \mathrm{CO}_{3}$ in Figure $7(\mathbf{a})$.

In summary, it was shown that rm aldolase and sp aldolase interacted with PFK-1s from rabbit, chicken, and fish in a similar manner. Both rm aldolase and sp aldolase prevented activity losses due to dilution and due to inhibitions by ascorbate, by AA fatty acid derivatives, and by monovalent carbonate salts. In some instances, sp aldolase was better than rm aldolase in preventing activity losses and in others sp aldolase was better.

It was shown by others [21-24] that aldolase from spinach was closely related to the Class I (non-metallic) aldolases found in eukaryotes. The close relationships among Class 1 aldolases were based upon immunological cross-reactions, chemical similarities, and structural similarities.

The $\mathrm{cm}$ and fm PFK-1 inhibitions by AA and preventions of inhibition by rm aldolase support the proposed role of AA as a facilitator of glycogen synthesis [2] in other species. Reports of faulty glycogen synthesis in uncompensated diabetics may be explained by the lack of AA in muscle [25-32]; AA requires the same mechanism for entry into muscle as glucose. The muscle of the uncompensated diabetic has been described as having tissue scurvy [31].

This study supports reports of similarities of aldolase isolated from spinach leaves and aldolases isolated from mammalian muscle tissues. These similarities include catalytic properties [21]; amino acid sequence [23]; and immunological similarities [22]. This study adds to similarities of $\mathrm{rm}$ aldolase and $\mathrm{sp}$ aldolase since both interact with rm PFK-1, suggesting the existence a conservation interrelationship between PFK-1s and the aldolases among several species.

\section{ACKNOWLEDGEMENTS}

The projects described were supported by Grant Number P60 MD00220 from the San Diego EXPORT, NCMHD, NIH; by Grant Number 1 R25 GM73590 of the UCSD CURE Program, National Cancer Institute, NIH; by Grant Number R25 GM083275 UCSD IMSD Program National Institute of General Medical Sciences, NIH; by Grant Number D34HP18954 the Hispanic Center of Excellence, Health Resources and Services Administration, and by Grant Number D18HP10623 Health Career Opportunities Program, Health Resources and Services Administration. Its contents are solely the responsibility of the authors and do not necessarily represent the official views of the National In- 
stitutes of Health.

\section{REFERENCES}

[1] Liu, J., Zhang, X., Yang, F., Li, T., Wei, D. and Ren, Y. (2006) Antimetastatic effect of a lipophilic ascorbic acid derivative with antioxidation through inhibition of tumor invasion. Cancer Chemotherapy and Pharmacology, 57, 584-590. http://dx.doi.org/10.1007/s00280-005-0073-9

[2] Russell, P., Williams, A., Marquez, K., Tahir, Z., Hosseinian, B. and Lam K. (2008) Some characteristics of Rabbit muscle phosphofructokinase-1 inhibition by ascorbate. Journal of Enzyme Inhibition and Medicinal Chemistry, 23, 411-417. http://dx.doi.org/10.1080/14756360701611621

[3] Russell, P.J., Williams, A., Amador, X. and Vargas, R. (2004) Aldolase and actin protect rabbit muscle lactate dehydrogenase from ascorbate inhibition. Journal of Enzyme Inhibition and Medicinal Chemistry, 19, 91-98. http://dx.doi.org/10.1080/14756360310001623309

[4] Struneck, A., Patočka, J. and Sarek, M. (2005) How does lithium mediate its therapeutic effects? Journal of Applied Biomedicine, 3, 25-35.

[5] Kajda, P.K. and Birch, N.J. (1981) Lithium inhibition of phosphofructokinase. Journal of Inorganic Biochemistry, 14, 275-278.

[6] Nordenberg, J., Kaplansky, M., Beery, E., Klein, S. and Beitner, R. (1982) Effects of lithium on the activities of phosphofructokinase and phosphoglucomutase and on glucose-1,6-diphosphate levels in rate muscles and liver. Biochemical Pharmacology, 31, 1025-1031. http://dx.doi.org/10.1016/0006-2952(82)90338-0

[7] Rodriguez-Gil, J.E., Fernandez, J.M., Barbera, A. and Guiovart, J.J. (2000) Lithium's effects on rat liver glucose metabolism in vivo. Archives of Biochemistry and Biophysics, 375, 377-384. http://dx.doi.org/10.1006/abbi.1999.1679

[8] Klein, P.S. and Melton, D.A. (1996) A molecular mechanism for the effect of lithium on development. Proceedings of the National Academy of Sciences of the United States of America, 93, 8455-8459. http://dx.doi.org/10.1073/pnas.93.16.8455

[9] Mann, L., Heldman, E., Shabltiel, G., Belmaker, R.H. and Agam, G. (2008) Lithium preferentially inhibits adenyl cyclase V and VII isoforms. International Journal of Neuropsychopharmacology, 11, 533-539.

[10] Kemp, R.G. (1975) Phosphofructokinase from rabbit skeletal muscle. In: Woods, W., Ed., Methods in Enzymology, Vol. 42C, Academic Press, New York, 71-77.

[11] Russell, P.J., Williams, A., Abbott, A., DeRosales, B. and Vargas, R. (2006) Characteristics of rabbit muscle adenylate kinase inhibition by ascorbate. Journal of Enzyme Inhibition and Medicinal Chemistry, 21, 61-67. http://dx.doi.org/10.1080/14756360500043372

[12] Morrissey, J.H. (1981) Silver stain for proteins in polyacrylamide gels: A modified procedure with enhanced uniform sensitivity. Analytical Biochemistry, 117, 307310. http://dx.doi.org/10.1016/0003-2697(81)90783-1
[13] Anderson, R.L., Hanson, T.E. and Sapico, V.L. (1969) D-Fructose-1-phosphate kinase and D-fructose 6-phosphate from Aerobacter aerogenes. The Journal of Biological Chemistry, 244, 6280-6288.

[14] Vassault, A. (1983) Methods of enzymatic analysis, enzymes I: Oxidoreductases, transferases Vol. III. Verlag Chemie, Basel, 118-126.

[15] Lebherz, H.G., Leadbetter, M.M. and Bradshaw, R.A. (1984) Isolation and characterization of the cytosolic and chloroplast forms of spinach leaf fructose diphosphate aldolase. The Journal of Biological Chemistry, 259, 10111017.

[16] Wilson, K. and Walker, J. (2001) Principles and techniques of practical biochemistry. Cambridge University Press, Cambridge, 319-204.

[17] Bradford, M.M. (1976) Determination of protein concentration in the manufacture and characterization of biopharmaceuticals. Analytical Biochemistry, 72, 248-254. http://dx.doi.org/10.1016/0003-2697(76)90527-3

[18] Russell, P., Williams, A., Abbott, A., Chadwick, J., Ehya F., Flores, R. and Hardamon, C. (2010) Effect of lithium salts on lactate dehydrogenase, adenylate kinase, and 1-phosphofructokinase activities. Journal of Enzyme Inhibition and Medicinal Chemistry, 25, 551-556. http://dx.doi.org/10.3109/14756360903357627

[19] Pelicano, H., Martin, D.S., Xu, R.-H. and Huang, P. (2006) Glycolysis inhibition for anticancer treatment. Oncogene, 25, 4633-4646. http://dx.doi.org/10.1038/sj.onc.1209597

[20] Herling, A., König, M., Bulik, S. and Holzhütter, H.-G. (2011) Enzymatic features of the glucose metabolism in tumor cells. FEBS Journal, 278, 2436-2459. http://dx.doi.org/10.1111/j.1742-4658.2011.08174.x

[21] Flurit, R., Ramasarma, T. and Horecker, B.L. (1967) Purification and properties of fructose diphosphate aldolase from spinach leaves. European Journal of Biochemistry, 1, 117-124.

[22] Kruger, I. and Schnarrenberger, C. (1983) Purification, subunit structure and immunological comparison of fructose-bisphosphate aldolases from spinach and corn leaves. European Journal of Biochemistry, 136, 101-106. http://dx.doi.org/10.1111/j.1432-1033.1983.tb07711.x

[23] Lebherz, H.G., Leadbetter, M.M. and Bradshaw, R.A. (1984) Isolation and characterization of the cytosolic and chloroplast forms of spinach leaf fructose diphosphate aldolase. The Journal of Biological Chemistry, 259, 10111017.

[24] Rutter, W.J. (1964) Evolution of aldolases. Federation Proceedings, 23, 1248-1257.

[25] Nikoulina, S.E., Ciaraldi, T.P., Abrams-Carter, L., Mudaliar, S., Park, K.S. and Henry, R.R. (1997) Regulation of glycogen synthase activity in cultured skeletal muscle cells from subjects with type II diabetes: Role of chronic hyperinsulinemia and hyperglycemia. Diabetes, 46, 10171024. http://dx.doi.org/10.2337/diab.46.6.1017

[26] Nikoulina, S.E., Ciaraldi, T.P., Carter, L., Mudaliar, S., Park, K.S. and Robert, R.H. (2001) Impaired muscle glycogen synthase in type 2 diabetes is associated with diminished phosphatidylinositol 3-kinase activation. The 
Journal of Clinical Endocrinology \& Metabolism, 86, 4307-4314. http://dx.doi.org/10.1210/jc.86.9.4307

[27] Shulman, G.I., Rothman, D.L., Jue, T., Stein, P., DeFronzo, R.A. and Shulman, R.G. (1990) Quantitation of muscle glycogen synthesis in normal subjects and subjects with non-insulin-dependent diabetes by $13 \mathrm{C}$ nuclear magnetic resonance spectroscopy. The New England Journal of Medicine, 322, 223-228. http://dx.doi.org/10.1056/NEJM199001253220403

[28] Henry, R.R., Ciaraldi, T.P., Abrams-Carter, L., Mudaliar, S., Park, K.S. and Nikoulina, S.E. (1996) Glycogen synthase activity is reduced in cultured skeletal muscle cells of non-insulin-dependent diabetes mellitus subjects. Biochemical and molecular mechanisms. Journal of Clinical Investigation, 98, 1231-1236. http://dx.doi.org/10.1172/JCI118906

[29] Halse, R., Bonavaud, S.M., Armstrong, J.L., McCormack, J.G. and Yeaman, S.J. (2001) Control of glycogen synthesis by glucose, glycogen, and insulin in cultured human muscle cells. Diabetes, 50, 720-726. http://dx.doi.org/10.2337/diabetes.50.4.720

[30] Chen, H., Karne, R.J., Hall, G., Campia, U., Panza, J.A., Cannon III, R.O., Wang, Y., Katz, A., Levine, M. and Quon, M.J. (2006) High-dose oral vitamin C partially replenishes vitamin $\mathrm{C}$ levels in patients with type 2 diabetes and low vitamin $\mathrm{C}$ levels but does not improve endothelial dysfunction or insulin resistance. American Journal of Physiology-Heart and Circulatory Physiology, 290, H137-H145.

http://dx.doi.org/10.1152/ajpheart.00768.2005

[31] Cunningham, J.J. (1998) The glucose/insulin system and vitamin C: Implication in insulin-dependent diabetes mellitus. Journal of the American College of Nutrition, 17, 105-108. http://dx.doi.org/10.1080/07315724.1998.10718734

[32] Will, J.C. and Byers, T. (1996) Does diabetes mellitus increase the requirement for vitamin C? Nutrition Reviews, 54, 193-202.

http://dx.doi.org/10.1111/j.1753-4887.1996.tb03932.x 